\title{
Political Quietism and the Sound of China Dream - The Urban Memory and Narrative of “1966 Cultural Revolution” in Shanghai in the Novel Flowers (Fan Hua)*
}

\author{
ZHANG Yunyan \\ Shanghai Jiaotong University, Shanghai, China; \\ XIE Zhangtian \\ Tsinghua University, Beijing, China
}

\begin{abstract}
During the 1966-1976 Cultural Revolution, the importance of collectivism completely overwhelmed the importance of individualism. This is one of the typical features of the totalitarian society, and it could be called "Political Quietism”. Flowers (Fan Hua) is one of the novels in contemporary China which try to explore and response such problems during the totalitarian society (MAO’s era) and after the totalitarian society (post-totalitarian or after MAO’s era).
\end{abstract}

Keywords: political quietism, China Dream, totalitarian society, post-totalitarian

\section{A Brief Introduction}

In August 2012, Jin Yucheng, a contemporary Chinese writer, published Flowers (Fan Hua) in a special issue of the journal Harvest, one of the most authoritative literature magazines in China. This novel caused great repercussions soon after its publication and won various awards given by authorities, including the 9th Mao Dun Literary Prize in 2015. In this novel, Jin Yucheng rewrites the urban memory of "Cultural Revolution" in Shanghai, conducting an artistic experiment with modified Shanghai (Wu) dialect. From a civilian perspective, he narrates and analyzes the daily life and political life of a group of failures in the urban area of Shanghai from the "Cultural Revolution" period to the 1990s, thus adding cultural and political considerations of "Cultural Revolution" to urban studies as well as providing a unique piece of evidence for the preservation of "Cultural Revolution” memory in urban context.

Jin Yucheng was born in Shanghai in 1952. As an "Educated Youth", he was sent down to farms in Heilongjiang Province as part of the "Up to the Mountains and Down to the Countryside Movement", which was initiated by the Chinese government in the 1950s and lasted until the end of "Cultural Revolution". Millions of Chinese youth were sent to rural areas to work as farmers during this period, willingly or under compulsion. The central government encouraged or compelled middle school students to participate in the

\footnotetext{
* Acknowledgements: This paper was sponsored by China National Social Science Foundation "Research on the Fundamental Problems of the Contemporary Aesthetics and Criticism Patterns” (15ZDB023).

ZHANG Yunyan, Ph.D., Lecture of Aesthetic and Cultural theory in Shanghai Jiaotong University. Email: zhangyunyan@sjtu.edu.cn

XIE Zhangtian, Department of Foreign Languages and Literatures, Tsinghua University. Email: xiezhangtian@sina.com
} 
movement because the National College Entrance Examination was suspended from 1966 to 1968 as a consequence of "Cultural Revolution", giving rise to social unrest and chaos. Jin Yucheng was not allowed to return to Shanghai until 1977. He started to publish novels since 1985 and became the editor of the journal Shanghai Literature in 1988. He did not become famous until the publication of Flowers (Fan Hua) in 2012.

Unlike many other contemporary Chinese writers who write in Mandarin, Jin Yucheng writes Flowers (Fan Hua) in creatively modified Shanghai dialect. He aims to create a new writing style apart from the mainstream mandarin writing so as to highlight regional features and diversity of the Chinese language. Meanwhile, he modifies the Wu dialect so that readers can understand the dialect without much difficulty. The plot and dramatic conflict of the novel are not dramatic, and no character can be considered as a protagonist. Instead, this novel puts its emphasis on the social changes of Chinese society and the history of revolution and reformation in Shanghai from 1960s to 1990s, depicting the love stories and experiences in the three decades of the “marginalized” Husheng, A’bao and Xiaomao, the later generation of proletarian revolutionary cadres, petty bourgeois and the working class. Being simply curious at first, they withdraw into themselves and finally lapse into disenchantment, which resonates with the author's own disillusionment with the disastrous "Cultural Revolution" and disappointment with the materialistic society after China carried out the "Reform and Opening Policy" in the 1980s.

\section{The Proposal of "Political Quietism”}

“Political Quietism” originates from “Quietism” in religious studies as that in Thomas Aquinas's theological theories. It is used symbolically in political science, leaving out the theological elements. Later scholars extracted this political conception when they explained Marx's concepts of history and ideology. The German Social Democrats adopted this explanation of history, believing that history, as a regular and automatic movement, does not need any political forces to interfere. They claimed that class struggle is a necessity of history and individual has no subjectivity in the course of history. Walter Benjamin presented a critique of German Social Democrats "Quietism" logic in Theses on the Philosophy of History, believing that "historical materialism" is just a puppet in philosophy. ${ }^{1}$ Related to the "winner" logic, "Political Quietism" also adheres to a certain ideology of linear historical progress, upon which Walter Benjamin casted doubts.

The sense of alienation and speechlessness felt by Husheng, A'bao and Xiaomao for those grandiose words, such as "cultural revolution”, "revolution”, "progress” and "class struggle”, is exactly their instinct doubt about and passive resistance against "political quietism". Husheng begins to be skeptical about it when his parents were moved out of Ladd's apartment because of entanglement in "Lin Biao Event" . (Lin Biao was a vice chairman of the Mao era, who disagreed with Mao Zedong and "1966 Culture Revolution", and dashed in Mongolia on Sept. 13, 1971, when he fled China with a plane. This is called "Lin Biao Event". See WiKipedia) When "political quietism" with the "winner" logic keeps victims from appealing, its historical rationality no longer exists.

As part of the generation who now live in a city where the political dissident and anti-Maoist Linzhao had lived, and who witnessed the executioners asking for the five-cent bullet fee from the political offender's

\footnotetext{
${ }^{1}$ Walter Benjamin :Theses on the Philosophy of History, Selected works of Benjamin, Beijing: China Social Science Press, 1999, p. 422

${ }^{2}$ Lin Biao was a vice chairman of the Mao era, who did not agree with Mao Zedong and "1966 Culture Revolution, and dashed in Mongolia on Sept. 13, 1971, when he fled China with a plane. This is called “Lin Biao Event”. See WiKipedia.
} 
family (it is also mentioned in the novel), Jin Yucheng "breaks the reality into pieces and makes a collage" of what he has experienced, which becomes the stories of Husheng, A'bao and Xiaomao, who are the epitome of the wasted in "Cultural Revolution”. "His memory, even if nostalgic, is blocked by cruel reality.”” He has a clear and distinctive view on nostalgia. "Chaojia” in "Cultural Revolution”, which confiscates people’s private properties by violence, only prospers the state-run thrift stores of Huaihai road, as evidenced by various old furniture and the rare antique violins, antique pianos and French couch. Jin Yucheng finds that "Great revolution brings great property transfer. The biggest thrift store in the Far East-the state-run thrift stores of Huaihai road, ushered a rare selling season. It is said that thieves often hid in the cupboard to commit robbery in the night, so the storekeeper had to patrol with a wolfhound every night." ${ }^{4}$ An abuse of power leads to a chain reaction of moral decline, even moral corruption.

\section{The Relation Between “Political Quietism” And “Flowers (Fan Hua)”}

Since Husheng, A’bao and Xiaomao are cautious and discontent with the progressive historical views and the "winner" historical logic, do they themselves manage to keep away from this inclination? Characters in Flowers love to engage in conversations and the novel is full of dialogues. However, they often fall silent while talking to people, which is called "buxiang" (make no sound) in the novel. "Buxiang" is indeed a frequently used term in Shanghai dialect, but its connotation is much more than this. It appears more than 1,500 times in the novel. Jin Yucheng explains, "I want to have a new style of writing after reading novels for so long. The personality of a novel is its language, including punctuation marks. Literature is all about people, so how should we describe them? I want to replace the prevailing technique of internal portrayal with dialogues. Chinese people are smart. They can understand everything. Everything can remain silent. Novels can be full of sounds, but I should be allowed to make no sound." ${ }^{5}$ He ends the novel with "buxiang” (no sound) of ordinary lives and starts with "buxiang” (no sound) of the other world.

He writes in the preface, "God did not make a sound, as if everything were up to me", which indicates that God exists in the novel but in absence. God's absence with "buxiang” (no sound) endows ordinary people with free will, leaving space for free choice and unconstrained development. When Husheng and his girlfriend Shuhua are discussing about the recently demolished Catholic Church near a school, a work shed of a statue of Mao Zedong springs up on the open space. A teacher commits suicide by colliding into a car and "a human eyeball solitarily rolls down the road with blood streaks, brains and drops of blood”. The grim reality converges with the God who is impervious to the reality, creating an appalling effect of being a witness. This is a metaphor, which can found in Xiaomao's experience. He finds solace in his relationship with Chunxiang, a Christian woman, after wistfully ending his love affairs with Yinfeng, a married woman. He continues to have relationship with a few other women, but Chunxiang is the woman who comes to his mind on his deathbed, indicating that God is eternal. This is an individual-level response to the conundrum of what the vulnerable individuals could do after the collapse of "Cultural Revolution's” faith system.

In this novel, Jin Yucheng's intention is more than putting forward the problems of faith. He attempts to demonstrate how the individual faith was imprisoned, trampled and alienated during the "Cultural Revolution",

\footnotetext{
${ }^{3}$ See Jin Yucheng from http://cul.sohu.com/20140327/n397283661.shtml.

4 "Flowers (Fan Hua)" illustrations of Inside pages

${ }^{5}$ See Jin Yucheng from http://cul.sohu.com/20140327/n397283661.shtml.

6 Flowers (Fan Hua), p.148, Shanghai Literature and Art Publishing House, 2014.
} 
using examples like building statues of the leader at various universities, leadership worship, and demolition of churches. He also depicts the conflict between disciples and authorities in detail. For example, the revolutionary masses burn down the Christians' cross, so the disciples can only make the sign of cross at the bottom of their hearts. God does not make a sound and is forced not to make a sound. Individual faith is doomed to death in an era that God makes no sound.

Although the external totalitarian regime forces the individual to "buxiang" (make no sound), does that mean the individual is absolutely incapacitated to protest positively and say "no"? On the one hand, Husheng, A'bao and Xiaomao passively eschew the surging tide of the revolution, which is a rational and prudent judgment. On the other hand, they fail to break away from the shackles of the historical tragedy and walk out of the shadow of violent "revolution", let alone acquire a stronger ability to participate in politics. They continue to withdraw from the public political area and go back to their small world to live a wretched and cynic life. The novel has an archetypal description of their attitudes. A'bao met his friend Husheng years after the revolution. Having gone through the vicissitudes of life, they reflect on the revolution. Husheng says: “I can't help asking whether revolution equals to sacrifice or not. The endless revolutions only result in more victims than before". A'bao says: "Some people sacrifice. Some people are the sacrificed. A slight change makes a big difference. I can't tell exactly whether my father sacrifices or is the sacrificed”. Husheng quotes a line from Hugo's Ninety-Three, saying that "a citizen's freedom sets the boundary of another citizens' freedom". ${ }^{7}$ The exchange between the roles of the sacrificed and those who sacrifice is exactly the exchange between the roles of the maltreated and those who maltreat. A'bao remains speechless this time-his silent approval of Husheng's words. The traditional Chinese tragic music "The Moon over a Fountain" and "Dielianhua" is played at this moment, which suits well with the bleak scenery. "They overlook towards the south by the window. The night breeze brings coolness. Blocks of roofs are in front of them. It is hard to tell the boundary of walls of the houses and roofing tiles of Shanghai, which are all in dark brown or grey. They extend themselves to the south and turn into the dark night. A few shorts float in the wind with pairs of gray-white wings. From this angle, the light of the distant Nanjing west road is dim, and we can't see the outline of the Pingan Cinema. Religious service has been resumed in Wyon hall but there is no light inside it. Only the flicking light from the Shanghai Exhibition hall seems like a yellow five-pointed star which stands alone with Soviet style steeple and the head of the tower, half-hidden in the sky.",

From the overlooking geographical perspective, the meaninglessness of this revolution and the messy residual sight are well depicted. This kind of revolution only leaves the ironic tragic scene. Husheng, A'bao and Xiaomao's social activities in the 1990s manifest their cynic attitudes after the revolution. The 1990s appears in the novel right after the revolution, skipping the 1980s, which makes it easier to make a contrast with the 1960s. It is reasonable to say that the 1990s best demonstrates the bad effects of the "Cultural Revolution" in 1960s, having typical characteristics of a post-totalitarian society. People are no longer excited about Utopian ideals and become apathetic about politics. They have no public life and they do not have any pursuit of social life. However, they do not lack of social entertainment, amusing themselves to death. Jin Yucheng describes the situation in the narrative of the urban area in Shanghai in the 1990s. The women who are closely related to Husheng, A'bao and Xiaomao suffer greatly in the pursuit of their desires, which shatters the illusion of

\footnotetext{
${ }^{7}$ Flowers (Fan Hua), p. 358.

${ }^{8}$ Flowers (Fan Hua), p. 359.
} 
materialistic pursuit and money worship in an era of rampant consumerism and proves the meaninglessness of those avaricious pursuits. This is a new version of "political quietism" in post-totalitarian China, succeeding the older version in the totalitarian society during the "Cultural Revolution".

\section{Flowers (Fan Hua) and "China Dream”}

Before Flowers (Fan Hua), Shanghai has been the setting and theme for many other novels, including Han Bangqing's Sing-song Girls of Shanghai, Eileen Chang's Flowers of Shanghai and Wang Anyi's The Enlightenment and Everlasting Regret. These novels emphasize the cultural flavor of "Haishang" (above the sea, another name of Shanghai), while Flowers (Fan Hua) highlights the political flavor of "Shanghai". The connotation of "Haishang" (above the sea) is closer to traditional culture, while "Shanghai" is related to the modern urban experience. Unlike other Chinese writers who often consider the motif of city/country and modern/traditional experience in a single-cultural, aesthetic and modern frame, Wang Anyi and Jin Yucheng depict Shanghai in a revolutionary and political sense. Yet these two writers are different. The protagonists in Wang Anyi's The Enlightenment show great heroism and revolutionary fervor. They identify themselves as the heroes of "The Great Proletarian Cultural Revolution" and therefore lack introspection. Flowers (Fan Hua), however, demonstrates meaninglessness of the revolution by telling the stories of a group of the marginalized, which is exactly the special meaning and value of this novel. Its meaning and value are equally prominent when compared with films. Contemporary director Jia Zhangke records the urban cultural landscapes of Shanghai in his film I Wish I Knew (Haishang Chuanqi). In his documentary, he also records personal memories of Shanghai's historical and cultural changes in the recent one hundred years by interviews. Jia Zhangke's reason for naming the film I Wish I Knew (Haishang Chuanqi) rather than Shanghai Chuanqi is that he likes putting the image of "water" at the first place, and the word "Haishang" implies the flowing water and a sense of vicissitudes brought by rivers, which is more touching. Just because of this, Jia Zhangke weakens and ignores the more poignant political and historical memory. "Shanghai" appears more frequently in Flowers (Fan Hua), and the place name "Shanghai" contains political, geographical and administrative meaning. "Shanghai" in Husheng, A'bao, and Xiaomao's world is a politically sensitive place, which has a special charm. This special charm is also embodied in the protagonists of the novel. Although both of these two works receive clamors of comments, the 18 interviewees chosen by Jia Zhangke are those famous people who are prominent in Shanghai's history, such as Taiwan director Hsiao-Hsien Hou, writer Han Han and the like. Although he claims that "I hope audience will have such a feeling that in historical changes, in various wars and political revolutions, each individual, no matter rich or poor, noble or ordinary, is deeply affected and appears to be rather passive", ${ }^{9}$ the ordinary people "make no sound" in his film and all of their stories are forgotten. The memory missed by Jia Zhangke is embodied in detail in Flowers (Fan Hua), whose historical scenario is rich and complex. Voices of the unknown and the failed are heard in the novel. These voices, which cannot be heard in I Wish I Knew, represent a unique voice of Shanghai.

Then emerges a problem. Though Husheng, A'bao and Xiaomao feel antipathy against "political quietism", they are addicted to it at the same time. Hence, does Jin Yuchengreally examine their state while feeling sympathetic for them? When the main characters in the novel make no sound, they are actually making responses in an ironical way. They make no sound because they feel powerless and inferior, or frustrated and

9 Jia Zhangke, Shenzhen Evening News, 01/07/ 2010. 
desperate, when confronting with the great political power. However, how to encourage people who went through the "Mao Era" to positively participate in politics in a new era and regain political ability after the “Cultural Revolution”, is not recounted in Jin Yucheng's narrative of the 1980s. Perhaps Jin Yucheng himself does not have an answer to this question. If the main characters in Flowers (Fan Hua) as well as the writer himself can't get away from the limitation of established economic interests, and base on the openness of civil society, take the needs of the individual's sympathy and communication, the production and creation of material and spirit, the reconstruction of the moral belief system and so on in the social construction of civil society, and realize the goal that "the public realize their 'rational communication' and the ability of cooperation by language interaction” in Harbermas' Structural changes in the public domain, so whether such sound of Shanghai can accommodate Xi's “China Dream” sufficiently is surely a difficult problem. We may as well recall the sound of the tin drums and the secret of Oscar's scream in German author Gunter Glass's The Tin Drums. Only when we sufficiently and thoroughly reflect on the origins of a totalitarian system can we develop a powerful system that can fight against it. Only after responding to the clamor of "revolution" in a totalitarian society and "farewell to revolution" in a post-totalitarian society can the utopian fantasy of "China dream” be possible to realize. This is the inspiration we can learn from Flowers (Fan Hua).

\section{References}

Walter Benjamin. (1999). Theses on the Philosophy of History, Selected works of Benjamin. Beijing: China Social Science Press. Wang Anyi. (2014a). The Age of Enlightenment. Beijing: People’s Literature Publishing House. Wang Anyi. (2004b). Everlasting Regret. Beijing: People’s Literature Publishing House. 